\title{
Large Ovarian Dermoid Cyst in Pregnancy with Successful Pregnancy Outcome: A Case Report
}

\author{
F. D. H. Olalere *, T. O. Kuye, J. O. Agbara, A. F. Tijani
}

\begin{abstract}
Large mature teratoma (Dermoid cysts) in pregnancy is rare, occurring in 1 in 1000 pregnancies. A 26-year-old Gravida 6, Para 2+3(2alive) woman, post caesarean pregnancy at term, presented with clinical and Ultrasound scan diagnosis of a large, symptomatic rapidly growing and complex left cystic ovarian mass of a month duration. Obstetrics findings were normal. Exploratory laparotomy with ovarian cystectomy was done and a live female infant weighing $2.65 \mathrm{~kg}$ was delivered by caesarean section. Histopathology analysis showed benign mature ovarian cystic teratoma with corpus luteum cyst. The patient and infant had uneventful post-operative recovery and were discharged 7 days later. Both were well at 4 weeks of follow up and were discharged to the gynecology and family planning clinic for ongoing follow up. Dermoid cyst is a possible differential in a rapidly growing adnexal mass coexisting with pregnancy. Prompt surgical intervention should be considered to achieve successful pregnancy outcome.
\end{abstract}

Index Terms - large, ovarian cyst, dermoid, pregnancy outcome.

\section{INTRODUCTION}

An adnexal mass may coexist with $0.2-2 \%$ of all pregnancies and are usually found incidentally at antenatal ultrasonography or caesarean section. ${ }^{1}$ In the first trimester, most of these masses are functional ovarian cysts and generally resolve spontaneously, but may persist in 0.7 to $1.7 \%$ of women throughout the pregnancy. ${ }^{2,3}$ Beyond 16 weeks gestation, dermoid cyst and cystadenoma constitute about $60 \%$ of adnexa masses persisting during pregnancy. ${ }^{2}$ Dermoid cysts or mature cystic teratoma are the most common type of ovarian germ cell tumor occurring in the reproductive age group. Dermoid cyst is known to be slow growing tumor at $1.8 \mathrm{~mm}$ per year and rapid growth to very large size is rare. The report is intended to raise awareness of this occurrence as well as highlight steps towards achieving successful pregnancy outcome.

*Dr. Mrs. Folasade Dolapo Haleemah OLALERE, Obstetrics and Gynecology Department, Lagos State University College of Medicine,(LASUCOM),Ikeja,Lagos.Nigeria

Dr. Mrs. Taiwo Olufunmilayo KUYE, Obstetrics and Gynecology Department, Lagos State University College of Medicine,(LASUCOM),Ikeja,Lagos.Nigeria

Dr. Joy Onyinyechi AGBARA, Obstetrics and Gynecology Department, Lagos State University College of Medicine (LASUCOM), Ikeja, Lagos. Nigeria

Dr. Adeyemi Fatai TIJANI, Obstetrics and Gynecology department, Lagos State University Teaching Hospital, Ikeja, (LASUTH) Lagos. Nigeria.

\section{CASE REPORT}

An unbooked 26-year old woman, Gravida 6, Para $2^{+3}$ (2alive) and one previous caesarean section and a successful VBACS due to breech at term presented at 32-week gestation, presented with a recurrent abdominal discomfort and rapidly increasing abdominal swelling for one month. There was no history of change in bowel habit, early satiety, vomiting, history of weight loss or night sweat. Physical examination showed a young woman in mild respiratory distress, not pale, not dehydrated and temperature was $37.1^{\circ} \mathrm{C}$. She had bilateral pitting pedal edema. Blood pressure was $120 / 80 \mathrm{mmHg}$ and pulse rate 90 beats per minute. She had good air entry in both lung fields. Abdomen was grossly distended (Figure 1) with a healed pfannenstiel scar but no scar tenderness. There was generalized abdominal tenderness and uterine contents could not be palpated. Vaginal examination showed soft, posterior cervix and os was closed. The left adnexa was full, the right adnexa and pouch of Douglas were empty .

An ultrasound scan report suggested a large, complex left adnexal mass with an intrauterine fetus at 32 weeks gestation. Full blood count, urinalysis, electrolyte, urea and creatinine, and liver function tests were normal. A diagnosis of a suspected ovarian mass with coexisting pregnancy was made. The patient was placed on analgesics (paracetamol tablet $1 \mathrm{~g}$ thrice daily) and counseled for admission for further evaluations. He however defaulted admission until 6weeks later.

She re-presented six weeks later with increased severity of symptoms, She was tachypneic with respiratory rate of 40cycles per minute, dyspnea on mild exertion, orthopnea, temperature was $37^{\circ} \mathrm{C}$, anicteric, not dehydrated , no bleeding per vaginam, drainage of liquor and she felt fetal movement adequately. Abdomen was markedly distended and generally tender. Vaginal examination showed soft, posterior cervix, 2centimetre long, the cervical os was closed and the presenting part was vertex at station $0^{-2}$.

Blood group was $\mathrm{O}$ rhesus positive, full blood count, electrolyte, urea and creatinine were normal. Cancer antigen CA125 was 56 which was elevated. A repeat abdominopelvic USS showed a complex cystic mass measuring $15 \mathrm{~cm}$ in widest diameter arising from the left adnexa containing echogenic materials suggestive of dermoid cyst. There was an intrauterine viable singleton fetus at 38 weeks gestation in longitudinal lie and cephalic presentation. Estimated fetal weight was $3.1 \mathrm{~kg}$ and placenta was posterior. MRI was not done due to financial constraints, she was comanaged with the gynecology oncology unit, pathology unit for possible frozen section intra-operatively. She was counseled and consented to an exploratory laparotomy, ovarian cystectomy and lower segment caesarean section. Findings were mild adhesion of the omentum to the anterior abdominal wall, 
large left ovarian cyst $(60 \mathrm{~cm} \times 45 \mathrm{~cm})$ compressing the uterus (Figure 2) and omentum adherent to the uterus. There was no ascites. A live female baby in cephalic presentation, weighing $2.65 \mathrm{~kg}$ was delivered(figure5). The post-operative period was uneventful, and the patient and infant were discharged home 7days later. Histopathology of the cyst showed a multiloculated benign, matured cystic teratoma with corpus luteum cyst.

The patient was seen at follow up clinic at 2 and 6 weeks postoperatively and both mother and infant were well. Complete blood count, urinalysis and repeat CA125 were normal, she was discharged to the family planning clinic for contraception and gynecology clinic for ongoing follow up.

\section{DISCUSSION}

An adnexal mass may coexist with pregnancy in $0.2-2 \%$ of all pregnancies. ${ }^{1}$ About $25-36 \%$ of adnexal mass are ovarian cysts (dermoid cyst). ${ }^{2}$ Large ovarian dermoid cyst is rare in pregnancy accounting for only about $1 \%$ of ovarian cysts in pregnancy. ${ }^{1}$ Dermoid cysts or mature cystic teratoma are the most common type of ovarian germ cell tumor usually occurring in the reproductive age group. They are commonly unilateral and 10-12 \% can be bilateral. They are commonly multicystic and contain sebaceous fluid as well as tissue of three germ cell layers of ectoderm (skin, hair, brain), mesoderm (muscle, fat , teeth ,bone, and cartilage) and endoderm (mucinous and ciliated epithelium).These teratomas usually arise from the gonads but can been found anywhere in the body. Their site, size and clinical presentations are extremely variable. ${ }^{3}$ Dermoid cysts are usually small size, $\leq 6 \mathrm{~cm}$ and their growth in pregnancy is expected to be insignificant and hardly resulted into any complications in pregnancy and labour. ${ }^{4}$ They are considered slow growing tumors at rate of $1.8 \mathrm{~mm}$ per year in women of premenopausal women. ${ }^{5}$ However in the present report, the benign dermoid cyst rapidly increased in size (Fig.1) during pregnancy producing significant abdominal pain and tenderness, and respiratory distress. The cyst may well have been present in previous pregnancies but went undetected at ultrasound and previous caesarean section due the small size. Rapid growth has previously been thought to be a feature of malignant degenerations, cystadenoma, ovarian neoplasm or non-malignant dermoids. ${ }^{5,6}$ However, rarely, as in the present report, benign mature teratoma could present with rapid increase in size. Although the mechanism of rapid growth of mature teratomas in pregnancy is not clear, one report has suggested abnormal estrogen/progesterone receptors in dermoid cysts and hormonal changes during reproductive maturity which stimulate the sebaceous tissue within the cyst. ${ }^{7}$ With increasing accessibility and affordability of antenatal ultrasound scan in the first trimester, the incidence of ovarian masses during pregnancy has increased. Majority of them would resolve spontaneously in the first trimester. ${ }^{4}$ Ovarian masses $>5 \mathrm{~cm}$ diameter, especially with a solid component on imaging, are likely to be non-functional and should be referred to specialist gynecologist with oncology interest for further evaluation. ${ }^{8}$ The reliability of tumor markers in diagnosis of ovarian masses in pregnancy is often debated. When an ovarian mass is diagnosed in pregnancy, tumor markers such as CA-125 levels may help to distinguish between a benign or malignant lesion and can be used to evaluate treatment. However, decidua- and amnion cells also produce CA-125 resulting in higher CA-125 levels during pregnancy especially in the first and third trimester (respectively because of trophoblast invasion and detachment of the placenta). Tumor markers associated with germ cell tumors (e.g. AFP and b-hCG) and granulosa cell-tumors (Inhibin B and AMH) can also be elevated in normal pregnancy and can therefore only be used as follow-up 9 . Asymptomatic and benign cysts can be managed conservatively but persistent symptomatic ovarian cysts are at increased risk of torsion, dyspareunia, difficult defecation, bowel obstruction, malignant transformation, and peritonitis from rupture. ${ }^{2,10}$ Such symptomatic cysts require open (Fig.2,3 and 4) or laparoscopic surgical excision.

American College of Obstetrics and Gynecology guidelines state that adnexal masses diagnosed during pregnancy appear to have a very low risk for both malignancy and acute complications, and expectant management can be considered. ${ }^{11}$ However, in the present report, the cyst was quite large and symptomatic, compressing the uterus and its content, produced respiratory distress, abdominal discomfort and the cervix was not favorable for induction of labor. Hence, surgical intervention was considered the appropriate treatment. A suggested algorithm for the management of ovarian cyst ${ }^{9}$ in pregnancy is provided in Figure 6. Large Dermoid cyst in pregnancy are not common but should be considered in a patient with newly diagnosed rapidly growing adnexal mass. Surgical intervention should be considered in symptomatic patients to avoid the risk of complications and achieve successful pregnancy outcome.

Declaration of conflicting interests: None

Funding: None

\section{FIGURES AND ALGORITHM}

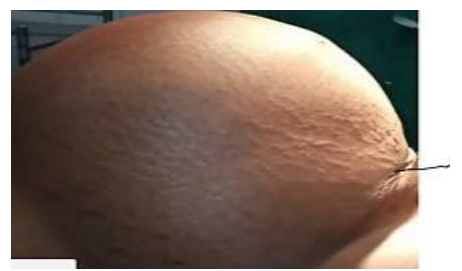

Fig.1: Markedly distended abdomen with ovarian cyst in pregnancy


Fig 2(a) and (b): Intraoperative findings of large ovarian cyst in pregnancy, during (a) and after(b) exteriorization of the cyst. 


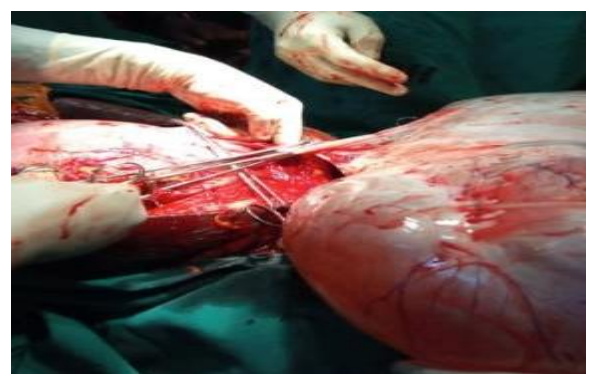

Fig. 3: ovarian cystectomy

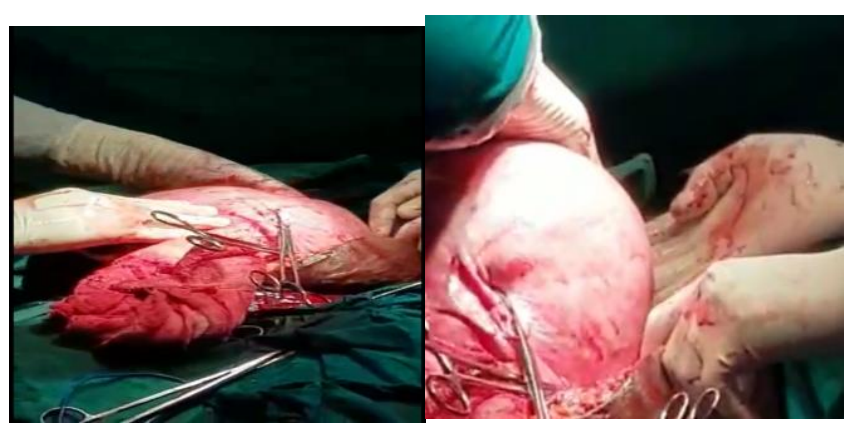

Fig.4(a) and (b): gravid uterus after cystectomy.

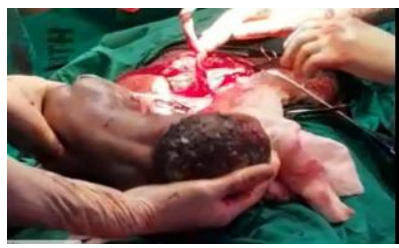

Fig.5: Caesarean delivery of the live baby girl after cystecomy

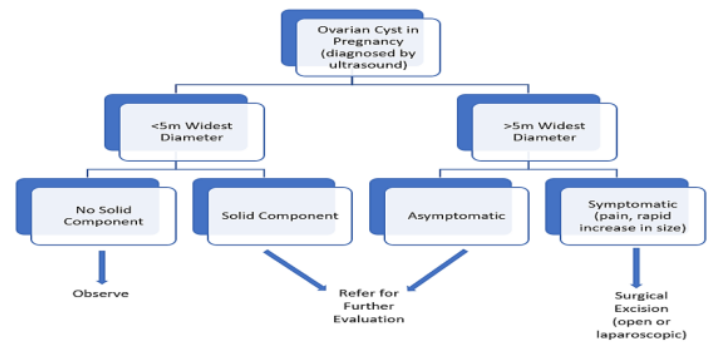

(a)

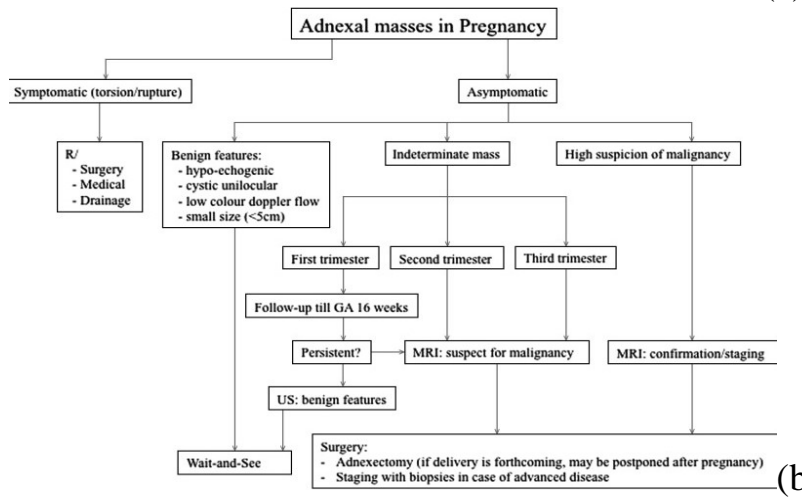

(b)

Fig.6 (a) and (b): Algorithm for management of ovarian cyst in pregnancy

\section{ACKNOWLEDGMENT}

We appreciate the assistance rendered by all doctors in the department of Obstetrics and gynecology, Lagos State University Teaching Hospital, LASUTH, and to Professor Ameh and Dr Y. A. Oshodi, for going through the drafted manuscript. Dr. Tijani Fatai for active participation in the patient management.

\section{REFERENCES}

[1] M. H. Basant, K.R. Rukmi, G. C. B. Prabhakar, "Giant ovarian cyst in term pregnancy-a rare case report,” Bali Med. J. vol. 4, 2015, pp. 5-7.

[2] J. R. Janna, K. Khanam, "A case of successful pregnancy outcome with a large ovarian cyst. a case report," Pulse vol.9, 2016, pp. 49-53.

[3] P. Pradhan, M. Thapa, "Dermoid cyst and its bizarre presentation." $J$ Nepal Med Assoc. vol. 52, 2014; pp. 837-844.

[4] B. Caspi, Z. Appleman , D. Roberson, G. Goldman, Z. Hagay, "Conservative management of ovarian cystic teratoma during pregnancy and labor,” Am. J. Obstet. Gynecol., vol. 182, 2000, pp. 503 -508 .

[5] D. Qurieno, F. Ghaneh, C. Michael, L. Ramit, G. Eugenio, M. John, "Benign rapidly growing ovarian dermoid cysts: a case series. Journal of Diagnostic Medical Sonography, vol. 33, 2016, pp.71-74.

[6] A. M. Schreck, H.F. Mikdachi, (2019, January 03) "Benign ovarian tumors in pregnancy: a case report of metachronous ipsilateral recurrent mucinous cystadenoma in initial pregnancy and mature cystic teratoma in subsequent pregnancy," Cureus vol. 11(1): e3818. doi:10.7759/cureus.3818 (Accessed 24 February 2020)

[7] A, C. Donnadieu, X. Deffieux, C. Le Ray, M. Mordefroid, R. Frydman, H. Fernandez, "Unusual fast growing ovarian cystic teratoma during pregnancy presenting with intracystic fat "floating balls" appearance," Fertil. Steril., vol. 86, 2006, pp. 1758-1759.

[8] J. Agah, E. R. Jafarzadeh, B. Kamalimanesh, M. A. Fattahi, A. R Jalilian, "Mismanagement of a huge ovarian serous cystadenoma in a young girl; a case report," Journal of Midwifery and Reproductive Health vol. 3, 2015, pp. 315-317.

[9] J. de Haan , M. Verheecke, F. Amant, “ Management of ovarian cysts and cancer in pregnancy," Facts Views Vis Obgyn., vol. 7(1), 2015, pp. 25-31.

https://www.ncbi.nlm.nih.gov/pmc/articles/PMC4402440/

[10] J. D. Black, D.M. Roque, M.C. Pasternak, "A series of malignant ovarian cancers arising from within a matured cystic teratoma: a single institution experience," Int. J. Gynecol. Cancer, vol. 25, 2015, pp. 792-797.

[11] A. Sinha, A. A. A. Ewies, "Ovarian mature cystic teratoma: challenges of surgical management," Obstetrics and Gynecology International, 2016. Available: https://doi.org/10.1155/2016/2390178 (Accessed 24 February 2020)

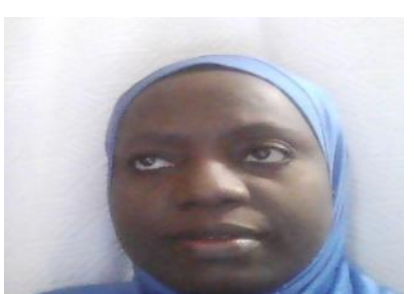

New Delhi 2015
MB; BS 2005 at the University of Ibadan, Nigeria

Available orcid: https://orcid.org/0000-0003-2486-4738

1.Maternal serum lipid in women with preeclampsia in Lagos: a case control $\underline{\text { study }}$

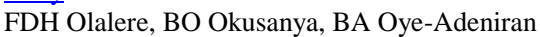

The Journal of Maternal-Fetal \& Neonatal Medicine 33 (5), 794-798

2. Y. A. Oshodi, J. O. Agbara, O. O. Ade-Fashola, F. M. Akinlusi, F.H Olalere, T.O. Kuye, "Weight gain and menstrual abnormalities between users of Depo-Provera and Noristerat",

International Journal of Reproduction, Contraception, Obstetrics and Gynaecology. Vol. 8(6), pp. 2226-2231. Medip Academy 
3. YA Oshodi, KA Rabiu, J. O. Agbara, C. A. Onyekwere F. M. Akinlusi, T. O. Kuye. F. D. H. Olalere, " Serum Visfatin in Preeclampsia and Normal Pregnancy in Lagos, South-Western Nigeria Journal of Advances in Medicine and Medical Research, vol. 29 (11) pp.1-8 2019

Member: World Association of Laparoscopic Surgeons, RCOG, Association of Gynaecologic Endoscopy Surgeons, Society of Gynecologist Of Nigeria, SOGON

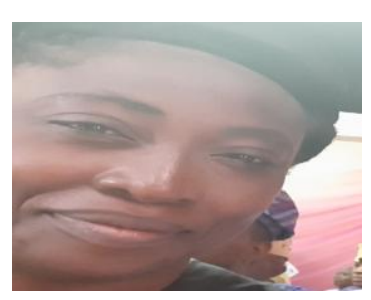

\section{Dr. Mrs. T. O. KUYE}

Lecturer 1,

Department of Obstetrics and Gynecology, Lagos State University College of Medicine.

Fellow of West African College of Surgeons

MB.Ch.BS 2003 at the Olabisi Onabanjo University Teaching Hospital, Sagamu.

1. Adegbola $\mathrm{O}$, Kuku T O. The factors affecting gestational age at booking in Lagos University Teaching Hospital, Lagos, Nigeria. J Clin Sci, vol. 12, 2015, pp. 20-3 2. Y. A. Oshodi, J. O. Agbara, O. O. Ade-Fashola, F. M. Akinlusi, F.H. Olalere, T.O. Kuye, "Weight gain and menstrual abnormalities between users of Depo-Provera and Noristerat", International Journal of Reproduction, Contraception, Obstetrics and Gynecology. Vol. 8(6), pp. 2226-2231. Medip Academy

3. YA Oshodi, KA Rabiu, J.O. Agbara, C. A. Onyekwere F. M. Akinlusi, T. O. Kuye. F. D. H. Olalere, " Serum Visfatin in Preeclampsia and Normal Pregnancy in Lagos, South-Western Nigeria Journal of Advances in Medicine and Medical Research, vol. 29 (11) pp.1-8 2019

Member: Society of Gynecologist of Nigeria, SOGON, NMA,

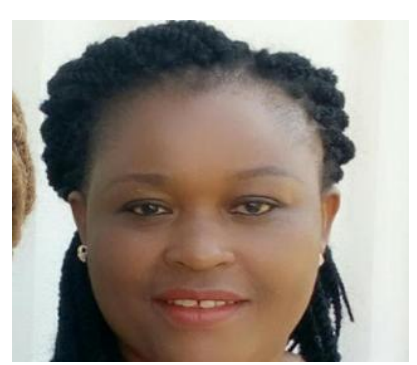

Dr. Mrs. J. O. Agbara

Lecturer 1,

Department of Obstetrics and Gynecology, Lagos State University College of Medicine.

Fellow of West African College of Surgeons

B.Sc., Anatomy, MB; BS at the Lagos

State University, MSc, 2003

RCOG part3 -in view

The Journal of Maternal-Fetal \& Neonatal Medicine 33 (5), 794-798

2. Y. A. Oshodi, J. O. Agbara ,O. O. Ade-Fashola, F. M. Akinlusi, F.H. Olalere, T.O. Kuye, "Weight gain and menstrual abnormalities between users of Depo-Provera and Noristerat",

International Journal of Reproduction, Contraception, Obstetrics and Gynaecology. Vol. 8(6), pp. 2226-2231. Medip Academy

3. YA Oshodi, KA Rabiu, J.O. Agbara, C. A. Onyekwere F. M. Akinlusi, T. O. Kuye. F. D. H. Olalere, "Serum Visfatin in Preeclampsia and Normal Pregnancy in Lagos, South-Western Nigeria Journal of Advances in Medicine and Medical Research, vol. 29 (11) pp.1-8 2019 Member: Society of Gynecologist of Nigeria, NMA, RCOG, AGES 